\title{
Methods of managing city transportations of passengers with disabilities
}

\author{
Kirill Safronov ${ }^{1, *}$, Eduard Safronov ${ }^{1}$, and Sergey Mochalin ${ }^{1}$ \\ ${ }^{1}$ Siberian State Automobile and Highway University, Mira 5, Omsk, 644080, Russia
}

\begin{abstract}
The article considers a control system for transportation of persons with disabilities and physically challenged people with the preset level of locomotion. This system is built with the help of modern tools of business modeling. A review of study results performed by the authors in the sphere of navigation showed that in spite of availability of modern navigation devices there are no easy-to-use indices reflecting route and vehicle accessibility. The authors developed a system of numerical evaluation of accessibility that will reflect a level of structure or service accessibility at various stages of adaptation, and will be easily understood by handicapped persons. This system can be used to build routes with the set level of passenger's locomotion, to provide statistic observations and manage the transportation system.
\end{abstract}

\section{Introduction}

In 2012, Russia ratified the UN Convention on Rights of Persons with Disabilities and thus assumed obligations to take all the necessary legal, administrative and other measures to guarantee the rights of people with special needs, especially concerning accessibility [1]. Accessibility is provided in the life-support system "housing - urban environment - transport infrastructure - objects of attraction". It is the transport infrastructure with its road network, transport facilities, rolling stock and management system that plays the key role in the process of people transportation.

According to the Recommendations of the RF Ministry of Transportation of September 2,2016 , and as it is required by the law, the following corporate managerial solutions should be developed and implemented: providing accessibility of transport infrastructure and vehicles with a set of required services for persons with disabilities, corporate staff training to work with such persons and other physically challenged people and to support them in different situations, cancelling of the operational acceptance (after July 1, 2016) of the structures, equipment and vehicles that cannot be easily and completely used by the persons with special needs as it is required by the Code of Practice 59.13330.2012, developing and enacting internal corporate plans for gradual increasing of accessibility index values of the existing structures and services. "Recommended Practice for Designing Activities on Providing Accessibility of the Road Facilities to Persons with Disabilities" published on the web-site of the Ministry of Transportation of the Russian Federation are expected to be used as a guidance. "Proportion of accessible structures in total amount of existing structures" is

\footnotetext{
${ }^{*}$ Corresponding author: transistem@rambler.ru
} 
currently used as an index of accessibility. However, this index has a number of shortcomings - the total amount of structures is changing, the structures cannot become accessible for the people immediately, this index cannot be used a statistic one while navigating and constructing accessible routes.

Hence, it is necessary to establish a universal index that would reflect a level of structure and service accessibility at various stages of adaptation, would be understood by handicapped persons and other users, would allow providing statistic observations, managing transportation process and building routes with the set level of accessibility.

\section{Literature review}

The article by Joseph et al. [2] presents wayfinding and navigation of people with disabilities, usage of personal devices and wireless data transfer that include familiarization, localization and orientation, path planning, path traversal, guidance, annotation, update and communication. Innovations in wayfinding and navigation technologies do not provide a uniform coverage of the transportation network for each category of the interested parties. Innovations in this sphere are usually oriented to the blind or visually impaired people [3]. Further efforts concerning developing applications for personal communication devices such as alerts for pedestrian-vehicle collisions and relaying information about bus route numbers are necessary in this field.

Two articles allow realizing the needs in navigation of the old, handicapped people and disabled veterans when they use transit services. Firstly, Montello \& Sas [4] survey human factors that are relevant to wayfinding and navigation but not connected with person's locomotion, which can be used by all the transit system users. Secondly, Thatcher et al. [5] focuses on the disabled people and aging population with visual, hearing and locomotion impairment.

These results lead to three problems to be solved: practical recommendations made by the system should be adapted to the individual needs of each user with the preset parameters of locomotion, presentation of the system and interaction with it should be adaptable to the particular user's capabilities. To provide the user with the appropriate and real-time advice and information, it is necessary for the system to know the exact coordinates of the user. Some problems are solved in a mobile project with the help of indoor navigation [6,7], for example, or personalized user interface design $[8,9]$.

To improve the GPS localization, various approaches have been developed such as AGPS, for example, or integration of GPS and WLAN [10]. In spite of the fact that localization quality was enhanced in many cases, Schlingensiepen et al. [11] experimentally revealed underproductivity of mobile devices. Solutions on the basis of GPS and WLAN [12] are not sufficient for the solid people's indoor support since localization must work reliably in complex and highly dynamic environments. Development of the navigation technologies for visually impaired and physically inactive passengers may include RFID tags and Bluetooth beacons installed at the bus stops and in public service vehicles. As a result, an identifier can code the route and the current position of the vehicle.

To provide a comparison of routes and finding a necessary route for a user, a penalty system with values from 8 to +10 was developed [11], with the values being distributed depending on the user's needs (from the need that is being avoid to the most necessary one) and according to the accessibility to the infrastructure elements (from "very hard to use" to "perfect"). This approach underlies some other accessibility evaluation techniques that represent linguistic characteristics of accessibility presented by persons with disabilities and use a 10-point scale [13].

These techniques have the following limitations: 
- there is a danger of subjectivity while issuing a qualitative description of the accessibility level, it is impossible to evaluate groups of structures;

- the data on the structures with a different amounts of zones to be evaluated are difficult to compare;

- the indices are difficult to interpret and statistically process, an overall evaluation of accessibility for a structure or a group of structures is impossible to obtain;

- the indices give little information, they are difficult to statistically process, it is difficult to economically analyze and use them on the accessibility maps, they are not suitable for assessment of efficiency of State programs, international projects, UN Convention.

A literature review conducted in the report [14] revealed absence of literature resources with discussions about wide-spread navigation technologies for old pedestrians and for those who are disabled veterans. We can conclude that problems with navigation and adaptation are caused, first of all, by lack of fundamental approaches to accessibility evaluation.

\section{Proposed method of accessibility evaluation}

The experience obtained while doing research on organization of handicapped people transport service showed that persons with disabilities are interested in information about accessibility of structures and services when they move outdoors [15]. That is why it was decided to take it as basis for considering the interests of disabled people. Before visiting some structures, the persons with disabilities were asked some questions (that were later generalized) in a fixed sequence. The respondents were offered to formally evaluate accessibility of some structures (from the least accessible structures to the most accessible ones). To convert linguistic indices into numerical parameters, fuzzy logic was used. Hence, the system of accessibility evaluation can be formulated with the help of the $\mathrm{Kd}$ accessibility coefficient according to the following scale:

- is the structure (service) accessible? The structure is not accessible, $\mathrm{Kd}=1$;

- is an unauthorized assistance necessary? The structure is accessible with an unauthorized assistance, $\mathrm{Kd}=2$;

- is the structure accessible without any assistance? The structure is accessible, $\mathrm{Kd}=3$.

The accessibility evaluation system developed can be employed to define the level of accessibility of vehicles, bus stops, bus stations and their elements, and other structures that are used by public transport passengers. Routes can be built with the preset coefficients of bus stops and vehicles accessibility within the existing management system.

\section{Results}

To describe business processes that reflect the real and projected activity of an enterprise, it is recommended to employ a modern tool of business modeling. Such a tool is UML (Unified Modeling Language [16]) that was used to develop a control system for transportation of disabled people (CSTDP) as a client-server application consisting of two modules and a database:

1. Module for controlling the passenger traffic of disabled people.

2. Module for optimal routing for disabled people.

3. CSTDP database.

This system is used by the transportation organizer, transporters, and persons with disabilities who plan and realize their public transport trips to the objects of attraction (Fig. $1)$. 


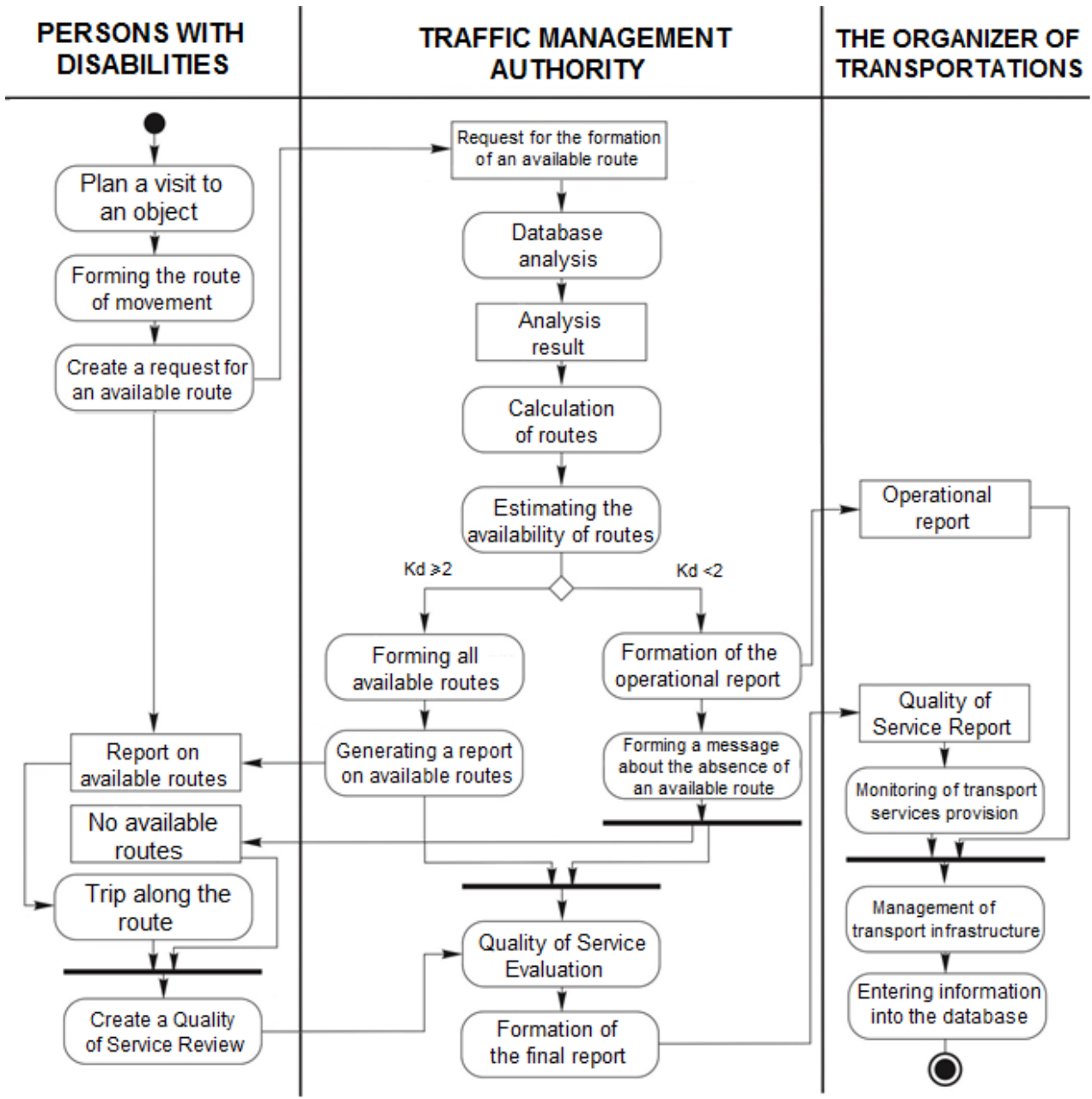

Fig. 1. Diagram of the control system for transportation of disabled people.

All the key transportation facilities are examined with respect to their accessibility and they are given the accessibility coefficient $(\mathrm{Kd})$.

In the first stage, a user plans a trip to an object of attraction and prepares a request for the route indicating his level of locomotion. After the preliminary determination of the possibility of complying with the request, it is processed with the help of a computer program that displays the real-time vehicular movement.

Subsequently, with the route to the objects of attraction having been worked out, a request for an optimal route is created with the module for optimal routing for disabled people, and then this request is transmitted to the module for controlling the passenger traffic of disabled people.

If it is possible to comply with the request, an appropriate route is chosen among those of the motor transport and city ground-based electric transport and compared with the user's request or the system chooses a route with a change, start and final time of the service is estimated and compared with the requested one, with the cost of service being taken into account. If there are no routes available, the processing is completed, the service quality and failure causes are rated. 
In this stage, if it is impossible to comply with the request, it can be redirected to the social taxi provider.

Based on the analysis of the information from the database, the module for controlling the passenger traffic of disabled people calculates possible routes for transportation of disabled people and the following route parameters:

- transportation time;

- start time;

- final time;

- number of necessary changes;

- time spent in waiting for a vehicle;

- number of necessary vehicles;

- number of modes of transport;

- distance between the first and the last stop;

- distance between the last stop and the object of attraction;

- accessibility coefficient of the route created.

The route and the vehicle are chosen with respect to the level of user's locomotion, if there are no variants available, the user receives a message about the impossibility of complying with his/her request. The information on CSTDP functioning is entered into the CSTDP database. Feedback fixes or confirms the fact of compliance with the request and lets the user evaluate the quality of the service with the additional indices of passenger transport accessibility quality.

\section{Conclusions}

The developed CSTDP and the Kd accessibility coefficient can be used by a transportation organizer to monitor and control transportation of persons with disabilities. Based on the database reports, a fuzzy logic system allows evaluating accessibility of the passenger traffic system elements and quality of the service provided for persons with disabilities. Monitoring of disabled people transportation, evaluation of quality of the service provided for persons with disabilities will make it possible for the transportation organizer to solve the problems of managing the transport infrastructure in accordance with its accessibility for the persons with disabilities. Some elements of this system are being implemented to organize the transport service in Omsk, Russia.

\section{References}

1. Convention on the Rights of Persons with Disabilities, United Nations, http://www.un.org/ru/documents/decl_conv/conventions/disability.shtml

2. A.G. Joseph, S. Aaron, T.M. Ermine, D. Bernardine, R. Zachary, Accessible Transportation Technologies Research Initiative (ATTRI): Assessment of Relevant Research (The Robotics Institute Carnegie Mellon University, Pittsburgh, 2017)

3. M.W. Maier, E. Rechtin, The Art of Systems Architecting, 3rd Ed. (CRC Press, Washington DC, 2013)

4. D.R. Montello, C. Sas, Human Factors of Wayfinding in Navigation. In International Encyclopedia of Ergonomics and Human Factors (CRC Press/Taylor \& Francis, Ltd, 2006)

5. R. Thatcher, C. Ferris, D. Chia, J. Purdy, B. Ellis, B. Hamby, J. Quan, M. Golden, Strategy Guide to Enable and Promote the Use of Fixed-Route Transit by People with 
Disabilities, TCRP Report 163 (Transportation Research Board, Washington, D.C., 2013) http://www.trb.org/Main/Blurbs/170626.aspx

6. H. Linde, E. Naroska, G. Stromberg, Low cost resolution enhancement in hyperbolic localization, Proceedings of 2nd Joint Workshop on Positioning, Navigation and Communication 2005 (WPNC'05) \& 1st Ultra-Wideband Expert Talk (UET'05) (2005)

7. H. Linde, E. Naroska, G. Stromberg, T. Sturm, TDOA Localization of Unsynchronized Nodes, Proceedings of the 13th IST Mobile and Wireless Communications Summit 2004 (2004)

8. C. Ressel, Modellbasierte Generierung von personalisierten und adaptiven Benutzungsschnittstellen für integrierte Wohnumgebungen. First Edition (Lohmar, Josef Eul,Verlag, 2008)

9. C. Ressel, J. Ziegler, E. Naroska, Intelligent Environments, 2nd IET International Conference, 247-255 (2006)

10. W. Bejuri, W. Saidin, M. Bin Mohamad, M. Sapri, K. Lim, Lecture Notes in Computer Science 7802, 394-403 (2013)

11. J. Schlingensiepen, G. Stockmanns, E. Naroska, O. Christen, T. Bolten, Transport problems 10, 5-14 (2015)

12. N. Chang, R. Rashidzadeh, M. Ahmadi, Consumer Electronics, IEEE Transactions 563, 1860-1867 (2010)

13. L. Ringaert, Is Your Business Open to All? (Universal Design Institute, Faculty of Architecture. University of Manitoba, 2001)

14. A. Jonnalagedda, L. Pei, S. Saxena, M. Wu, B.-C. Min, E.A. Teves, A. Steinfeld, M.B. Dias, Enhancing the Safety of Visually Impaired Travelers in and around Transit Stations. Tech. Report CMU-RI-TR-14-28 (Robotics Institute, Carnegie Mellon University, 2014) http://ri.cmu.edu/publication_view.html?pub_id=7815

15. E.A. Safronov, K.E. Safronov, E.S. Semenova, Transportnaya infrastruktura gorodov $R F$. Issledovanie problem: monografiya (LAP LAMBERT Academic Publishing, 2017) ISBN-10: 3330089768

16. G. Buch, A. Yakobson, J. Rambo, UML Klassika CS, 2-e ed. (Peter, St. Petersburg 2006) 